\title{
RENDIMENTO DE AÇO LÍQUIDO NA AMT: ENTENDENDO, CONTROLANDO E OTIMIZANDO*
}

Bruno Rodrigues Henriques ${ }^{1}$ Odair José Kirmse ${ }^{1}$

\section{Resumo}

O entendimento, controle e otimização do rendimento de aço líquido, em uma aciaria LD, é uma tarefa complexa e desafiadora. Qualquer projeto que se disponha a otimizar o rendimento de aço líquido irá se deparar com enormes dificuldades técnicas e operacionais. A despeito de todas as dificuldades e em função da importância do rendimento de aço líquido, uma vez que o mesmo tem forte impacto no custo de produção, toda aciaria procura manter essa variável de processo sob estrito controle. Esse trabalho se propõe a mostrar todas as etapas da condução de um projeto, desenvolvido e implantado em 2014, que tinha como foco entender, controlar e otimizar o rendimento de aço liquido. Durante o desenvolvimento do projeto, foi encontrado um total de 19 desvios e foram implementadas 23 ações corretivas. O valor do rendimento, que antes do projeto estava em torno de $91,6 \%$, evoluiu para uma média de 93,5\% em 2015 e 2016. Esse aumento de 1,9\%, em média, no valor do rendimento de aço líquido, proporcionou uma expressiva redução no custo de produção na aciaria.

Palavras-chave: Aciaria; Rendimento de aço; Convertedor; Panela de aço.

\section{STEEL YIELD AT AMT: UNDERSTANDING, MANAGING AND OPTIMIZING}

\begin{abstract}
The understanding, control and optimization of liquid steel yield, in a steelmaking plant, is a complex and challenging task. Any project that is willing to optimize the liquid steel yield will be faced with enormous technical and operational difficulties. Despite all the difficulties and due to the importance of the liquid steel yield, since it has a strong impact on the production cost, all steelmaking plant seeks to maintain this process variable under strict control. This paper aims to show all the steps of driving a project, developed and implemented in 2014, which was focused to understand, control and optimize the liquid steel yield. During the development of the project, it was found a total of 19 deviations and were implemented 23 corrective actions. The value of liquid steel yield, that before the project was around $91.6 \%$, evolved to an average of $93.5 \%$ in 2015 and 2016 . This increase of $1.9 \%$, on average, in the liquid steel yield, provided a significant reduction of production cost in the steelmaking plant.
\end{abstract}

Keywords: Steelmaking; Steel yield; Converter; Steel ladle.

1 Metallurgical Engineer, M. Sc., Steelmaking Process Engineer at ArcelorMittal Tubarao, Vitória, ES, Brasil. 


\section{INTRODUÇÃO}

\subsection{APRESENTAÇÃO}

O entendimento, controle e otimização do rendimento de aço líquido, em uma aciaria LD, é uma tarefa complexa e desafiadora. Para alguns, trata-se de um dos temas mais áridos de uma aciaria. Essa variável operacional é tão complexa, que mesmo um simples procedimento de "benchmarking" entre usinas, torna-se quase inviável, uma vez que cada empresa adota uma fórmula de cálculo diferente para o estabelecimento do valor de rendimento de aço líquido de cada corrida produzida.

Qualquer projeto que se disponha a otimizar o rendimento de aço líquido irá se deparar com enormes dificuldades técnicas e operacionais. Variáveis importantes de processo que, em teoria, afetam o valor do rendimento, na prática não apresentam qualquer correlação. O FeT (Ferro Total) na escória é um exemplo perfeito para ilustrar essa tese. Parte da explicação para tamanha dificuldade de entendimento, controle e otimização do rendimento de aço líquido pode ser encontrada na conjugação dos seguintes fatores:

$\checkmark$ Existência de um grande número de variáveis, algumas sem qualquer tipo de controle, capazes de influir, decisivamente, no valor real do rendimento.

$\checkmark$ Interferência de uma variável, mascarando completamente o efeito de outra.

$\checkmark$ Dificuldades para a realização de experimentos de investigação, sem afetar o ritmo diário de produção da aciaria.

$\checkmark$ Limitações técnicas dos equipamentos de pesagem existentes.

$\checkmark$ Inexistência de procedimentos de pesagem, em etapas críticas do processo de produção da aciaria.

$\checkmark$ Restrições de capex.

$\checkmark$ Influência do mix de produção.

$\checkmark$ Falhas de contabilidade; entre outros.

A despeito de todas as dificuldades e em função da importância do rendimento de aço líquido, uma vez que o mesmo tem forte impacto no custo de produção, toda aciaria procura manter essa variável de processo sob estrito controle. Desvios de resultados são normalmente enfrentados através do desenvolvimento de projetos específicos, de média ou longa duração, com foco na correção da trajetória do valor real do rendimento.

\subsection{OBJETIVOS}

Esse trabalho se propõe a mostrar todas as etapas da condução de um projeto, desenvolvido e implantado em 2014, que tinha como foco entender, controlar e otimizar o rendimento de aço liquido. Ao mesmo tempo, também será apresentado todo o conhecimento gerado durante o desenvolvimento do projeto e os resultados alcançados. Para atingir os seus objetivos, o projeto possuía três metas específicas:

$\checkmark$ Conhecer e dominar o processo gerador do problema

$\checkmark$ Identificar desvios e propor ações corretivas

$\checkmark$ Posicionar o rendimento real acima do valor previsto no orçamento 


\subsection{CONCEITUAÇÃO TÉCNICA}

\subsubsection{PROCEDIMENTO DE CÁLCULO DO RENDIMENTO DE AÇO LÍQUIDO}

Como já foi informado anteriormente, cada aciaria possui um procedimento específico para o cálculo do valor de rendimento de aço líquido de uma corrida. Contudo, de forma geral, o rendimento de aço líquido pode ser definido pela equação 1 apresentada abaixo.

Rendimento de aço líquido $=($ Peso de Aço Líquido $/$ Carga Metálica $) \times 100$

$\mathrm{Na}$ definição da carga metálica, algumas empresas consideram, além do gusa líquido, todas as parcelas de materiais ferrosos adicionados em uma corrida, em todas as etapas do fluxo de produção da aciaria. Portanto, nesse caso, essas empresas consideram todas as adições de sucatas, minérios e briquetes ferrosos, ferro-ligas e materiais refrigerantes à base de ferro, adicionados antes e/ou após o vazamento da corrida no convertedor LD. Por sua vez, outras empresas consideram apenas os diversos tipos de sucatas adicionadas na fase de carregamento dos convertedores LD. Para esse segundo grupo de empresas, os materiais ferrosos adicionados durante e/ou após o vazamento da corrida não entram na contabilidade da carga metálica.

Nesse quesito, não há empresa certa ou errada. Trata-se, simplesmente, de filosofias diferentes de contabilidade. O importante é que os conceitos adotados se mantenham os mesmos por um longo tempo, de modo que seja possível comparar o rendimento atual com os valores obtidos no passado. Só assim será possível controlar e otimizar essa importante variável operacional de uma aciaria.

A definição do peso de aço líquido de uma corrida também varia de aciaria para aciaria. De forma geral, esse peso é definido através da pesagem da panela de aço com a ponte rolante ou com o próprio carro panela. O que pode variar é o momento em que a panela de aço é pesada. De novo, aqui não há empresa certa ou errada.

A AMT, na definição da carga metálica, se enquadra na segunda categoria de empresas citada acima, ou seja, a aciaria da AMT não considera a adição dos seguintes materiais:

$\checkmark$ Materiais refrigerantes (minério de ferro, sínter, briquetes ferrosos, etc) adicionados durante o sopro no convertedor LD.

$\checkmark$ Ferro-ligas adicionados durante o vazamento do aço no convertedor LD e/ou durante o tratamento das panelas nas estações de refino secundário.

$\checkmark$ Sucatas refrigerantes adicionadas durante e/ou após o vazamento da corrida.

Por sua vez, na AMT, a definição do peso de aço líquido é feita através da pesagem da panela com a ponte rolante, imediatamente antes da mesma ser posicionada na torre do lingotamento contínuo. Nesse momento é obtido o peso bruto da panela de aço. Para se chegar ao peso de aço líquido, a metodologia de cálculo desconta a tara da panela, o peso da tampa de panela e o peso de escória contida na panela. 


\subsubsection{INFLUÊNCIA DE VARIÁVEIS METALÚRGICAS NO RENDIMENTO}

A literatura indica que existe uma série de variáveis metalúrgicas, capazes de influir, decisivamente, no valor do rendimento de aço líquido. Dentre as principais variáveis, podem ser citadas as seguintes:

$\checkmark$ Composição química do aço

$\checkmark$ Volume de escória gerada durante o sopro no convertedor

$\checkmark$ Percentual de FeT (Ferro Total) na escória

$\checkmark$ Nível de oxidação da corrida

$\checkmark$ Padrão de sopro (distância banho-lança e vazão de oxigênio)

$\checkmark$ Índice de projeção de aço

$\checkmark$ Índice de formação de cascão na lança de oxigênio

$\checkmark$ Índice de retenção de aço no convertedor, após vazamento

$\checkmark$ Índice de eficiência do sopro combinado

Em teoria, pode-se calcular o efeito isolado de cada uma dessas variáveis. Contudo, ao se sair do campo teórico para a prática operacional, verifica-se que não existe a atuação isolada de uma variável, e sim a influência conjunta de todas as variáveis no rendimento de aço líquido, com uma variável metalúrgica interferindo, positiva ou negativamente, no efeito de outra. Nesse caso, a questão se complica bastante, uma vez que torna-se muito difícil verificar, na realidade fria dos dados de processo, aquilo que a literatura indica com um fato consumado.

Tome-se, como exemplo, a variável metalúrgica "percentual de FeT na escória de fim de sopro". Essa variável informa a quantidade de ferro que foi oxidada durante o sopro de oxigênio no convertedor LD e que passou a fazer parte da escória de fim de sopro. Na teoria, quanto maior o teor de FeT na escória de fim de sopro, menor deveria ser o rendimento de aço líquido, uma vez que uma maior parcela de ferro foi oxidada e migrou para a escória, ao invés de permanecer no aço líquido. Contudo, na prática, em função da influência de todas as outras variáveis, não se consegue ver qualquer correlação entre o teor de FeT da escória e o rendimento.

A Figura 1, com dados de todas as corridas produzidas de jan/16 a jul/16 na AMT, apresenta o relacionamento entre o teor de FeT da escória de fim de sopro e o rendimento de aço líquido. Verifica-se que não há qualquer correlação.

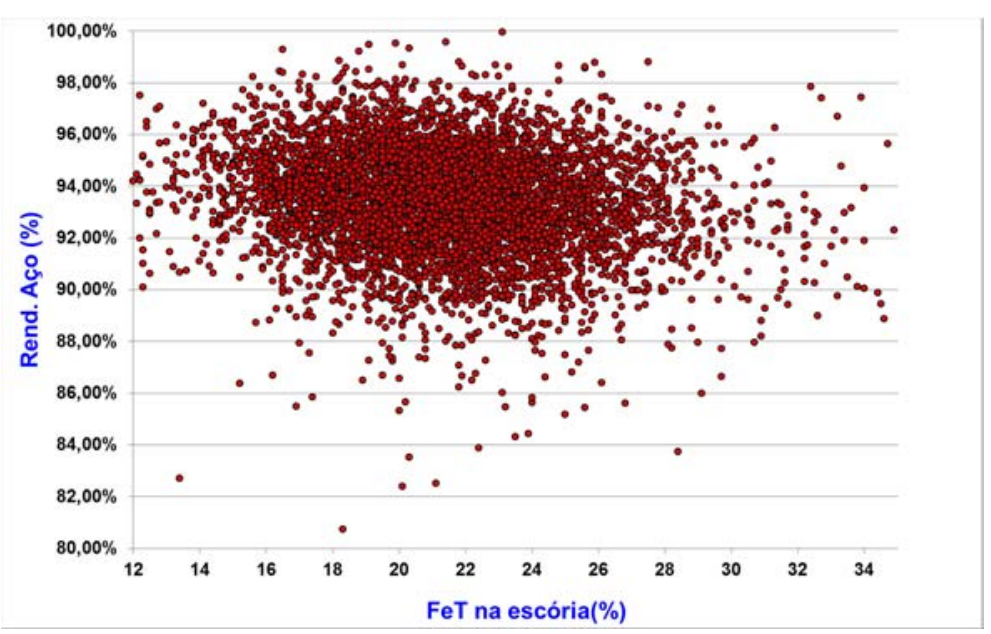

Figura 1. Rendimento de aço líquido em função do FeT da escória, para todos os tipos de aços 
Poderia se argumentar que o gráfico da Figura 1 não utiliza uma premissa correta, uma vez que considera todos os tipos de aços, com teores de $\mathrm{C}$, Si, Mn e elementos de liga completamente diferentes. Portanto, com o objetivo de se fazer uma avaliação mais focada, através da eliminação do efeito da composição química do aço, a Figura 2 mostra o relacionamento entre o teor de FeT na escória de fim de sopro e o rendimento de aço líquido, desta vez considerando apenas um tipo de aço ultra baixo carbono, com teor de C de 15ppm e de Mn de 0,12\%. Constata-se, novamente, que não há qualquer correlação entre as duas variáveis.

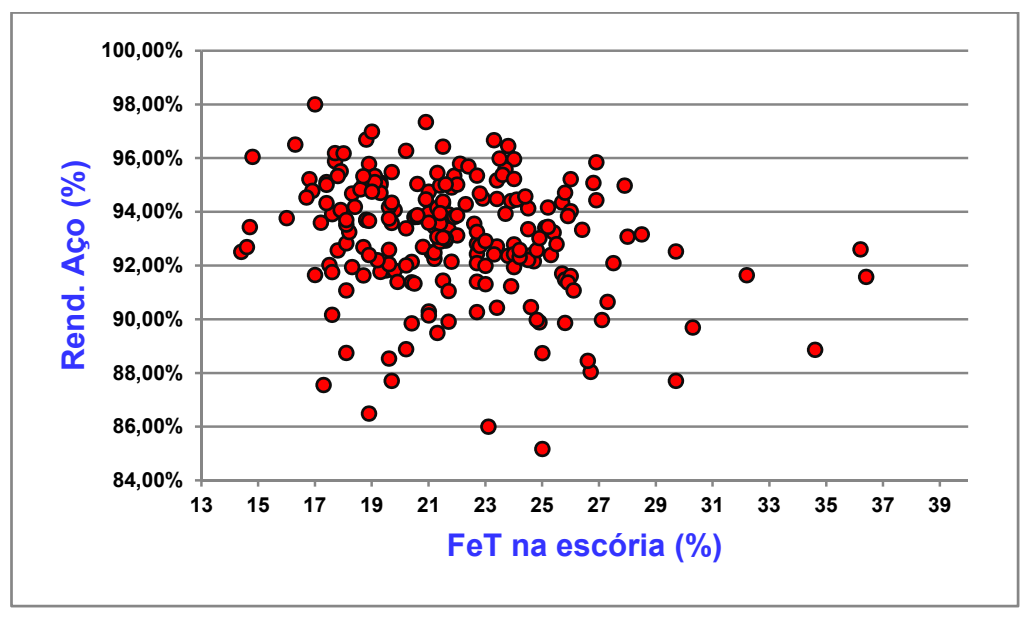

Figura 2. Rendimento de aço líquido em função do FeT na escória, em aços UBC

Pode-se avaliar a correlação do rendimento de aço líquido com diversas outras variáveis metalúrgicas. A Figura 3 apresenta o relacionamento entre a adição de minério de ferro durante o sopro no convertedor e o rendimento de aço líquido, novamente considerando todas as corridas produzidas de jan/16 a jul/16 na AMT. De novo, verifica-se que não há qualquer correlação.

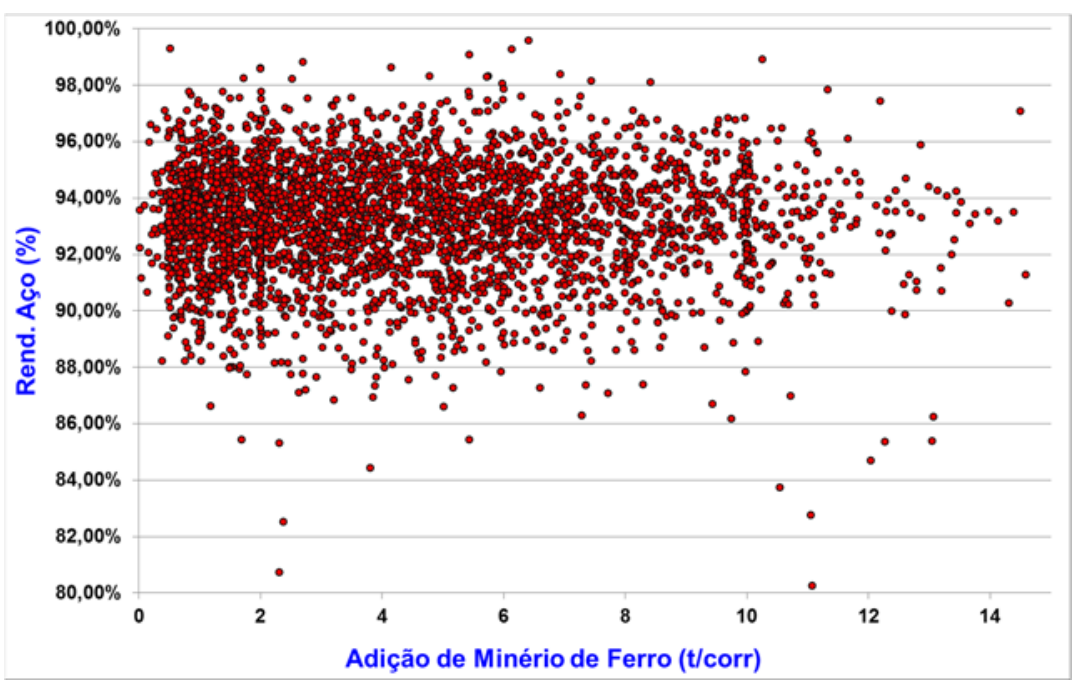

Figura 3. Rendimento de aço líquido em função da adição de minério de ferro, em todos os aços

Aí está a dificuldade de se entender, controlar e otimizar o rendimento de aço líquido. Variáveis importantes, como o teor de FeT na escória e a adição de minério de ferro durante o sopro, não produzem efeitos fortes o suficiente para suplantar os 
efeitos de todas as outras variáveis. Nesse cenário, encontrar as causas básicas que seriam as responsáveis por períodos de baixos rendimentos de corridas é uma tarefa desafiadora, que só pode ser enfrentada através de desenvolvimento e implantação de projetos específicos.

\subsubsection{ASPECTO CONTÁBIL DO RENDIMENTO DE AÇO LÍQUIDO}

O rendimento de aço líquido possui, basicamente, duas dimensões: física e contábil. A importância da dimensão física já foi apresentada anteriormente. Contudo, a dimensão contábil não pode ser negligenciada. Ela é tão relevante quanto a dimensão física. Para o rendimento de aço líquido, tão importante quanto reduzir o teor de FeT da escória é garantir que todos os cálculos e pesagens de materiais apresentem elevados índices de confiabilidade.

Qualquer projeto que almeje o sucesso precisa conhecer, em profundidade, todas as metodologias de cálculo utilizadas na definição do valor de rendimento de uma corrida. Existe um complexo fluxo de dados entre os diversos níveis do sistema de informações de cada usina. É extremamente importante investigar e eliminar todo e qualquer desvio nesse fluxo, garantindo que o mesmo passe a apresentar um elevado nível de robustez.

Outro aspecto muito importante é a garantia da confiabilidade de todas as pesagens, seja a pesagem de todos os materiais adicionados na corrida, seja a pesagem da carga metálica (gusa líquido + sucata) ou do próprio aço líquido. A pesagem da carga metálica e do aço líquido sofre influência do layout da aciaria e da disponibilidade e posicionamento dos diversos dispositivos de pesagem.

Para a completa rastreabilidade do rendimento de aço líquido, o ideal seria que houvesse dispositivos de pesagem da carga metálica e do aço líquido nos mais diversos pontos do fluxo operacional de uma aciaria. Desse modo, uma etapa do fluxo operacional poderia checar a confiabilidade de pesagem da etapa anterior, atuando como um elemento auditor do processo e fornecendo subsídios valiosos para qualquer procedimento de investigação. Contudo, essa não é a realidade presente na maior parte das aciarias do mundo. Aí está outra razão para a dificuldade de se entender, controlar e otimizar o rendimento de aço líquido.

O posicionamento, no fluxo operacional da aciaria, dos diversos dispositivos de pesagem da carga metálica e do aço líquido, varia de empresa para empresa. $\mathrm{Na}$ AMT, os procedimentos e os dispositivos de pesagem disponíveis são os seguintes:

$\checkmark$ Pesagem da panela de gusa líquido, através de duas balanças situadas nos dois poços de gusa, imediatamente após o descarregamento do gusa líquido do carro torpedo para a panela de gusa e antes do processo de remoção de escória da panela de gusa.

$\checkmark$ Pesagem dos diversos tipos de sucatas na área do pátio de sucata, através de balança específica para essa finalidade.

$\checkmark$ Pesagem da panela de aço líquido, através de duas pontes rolantes situadas entre as alas do refino secundário e do contínuo, imediatamente antes do posicionamento da panela de aço na torre do lingotamento contínuo. 


\section{MATERIAIS E MÉTODOS}

Durante a condução do projeto foi utilizada a metodologia "Six-Sigma" de análise e solução de problemas, sendo que o desenvolvimento do projeto contemplou dez etapas, que são apresentadas a seguir:

I. Identificação do problema

II. Entendimento da metodologia de cálculo do rendimento de aço líquido

III. Avaliação da robustez e confiabilidade do fluxo de dados, responsável pela definição do valor do rendimento de aço líquido

IV. $\quad 1^{\text {a }}$ etapa de identificação de desvios, com base nas três etapas anteriores

V. Realização de experimento, contemplando todo o fluxo operacional da aciaria, visando identificar o processo gerador do problema de baixo rendimento

VI. $\quad 2^{\mathrm{a}}$ etapa de identificação de desvios, com base no experimento anterior

VII. Proposição e implantação de ações corretivas para cada desvio encontrado

VIII. Acompanhamento e divulgação dos resultados obtidos após a implantação das ações corretivas

IX. Treinamento de todos os operadores e supervisores que estavam envolvidos no processo gerador do problema de baixo rendimento, contemplando desde a área de dessulfuração do gusa líquido até a área de lingotamento contínuo

X. Consolidação do conhecimento gerado através da criação e revisão de diversos padrões técnicos

\subsection{REALIZAÇÃO DE EXPERIMENTO NA ACIARIA}

Trata-se de uma das etapas mais importantes do desenvolvimento do projeto. A avaliação "post mortem" de causas de baixo rendimento de uma corrida não é uma tarefa fácil, uma vez que alguns desvios causadores do problema podem ser impossíveis de serem rastreados após a realização da corrida. Portanto, ficou claro que a detecção de desvios importantes, assim como a avaliação dos diversos dispositivos de pesagem existentes na aciaria, só seriam possíveis através da realização de procedimentos experimentais no "chão de fábrica" da aciaria. $O$ experimento foi realizado durante três dias, com a participação de 8 especialistas, posicionados em pontos estratégicos do fluxo de produção de aço, inclusive dentro das cabines das diversas pontes rolantes da aciaria. Esses especialistas puderam acompanhar "in loco" todas as etapas do fluxo de produção de várias corridas.

\section{RESULTADOS E DISCUSSÃO}

\subsection{IDENTIFICAÇÃO DO PROBLEMA}

O resultado obtido na etapa de identificação do problema, que mostra a situação do rendimento de aço líquido antes do início do projeto, pode ser avaliado através da Figura 4, mostrada a seguir. Nota-se que o rendimento de aço líquido vinha caindo, em todos os tipos de aços, desde julho/2010. A Figura 4 indica que houve duas quedas importantes, que podem ser descritas da seguinte maneira:

\footnotetext{
$\checkmark 2010$ a 2011: queda de cerca de $0,6 \%$ no rendimento

$\checkmark$ 2012: comportamento igual ao ano de 2011

$\checkmark 2012$ a 2013: queda de cerca de $0,6 \%$ no rendimento
} 
A conclusão extraída desse resultado é a de que estava ocorrendo um conjunto de problemas estruturais, interferindo em uma ou mais etapas do processo de produção de aço líquido e que, por isso mesmo, foi capaz de afetar todos os tipos de aços simultaneamente e por um longo período de tempo.

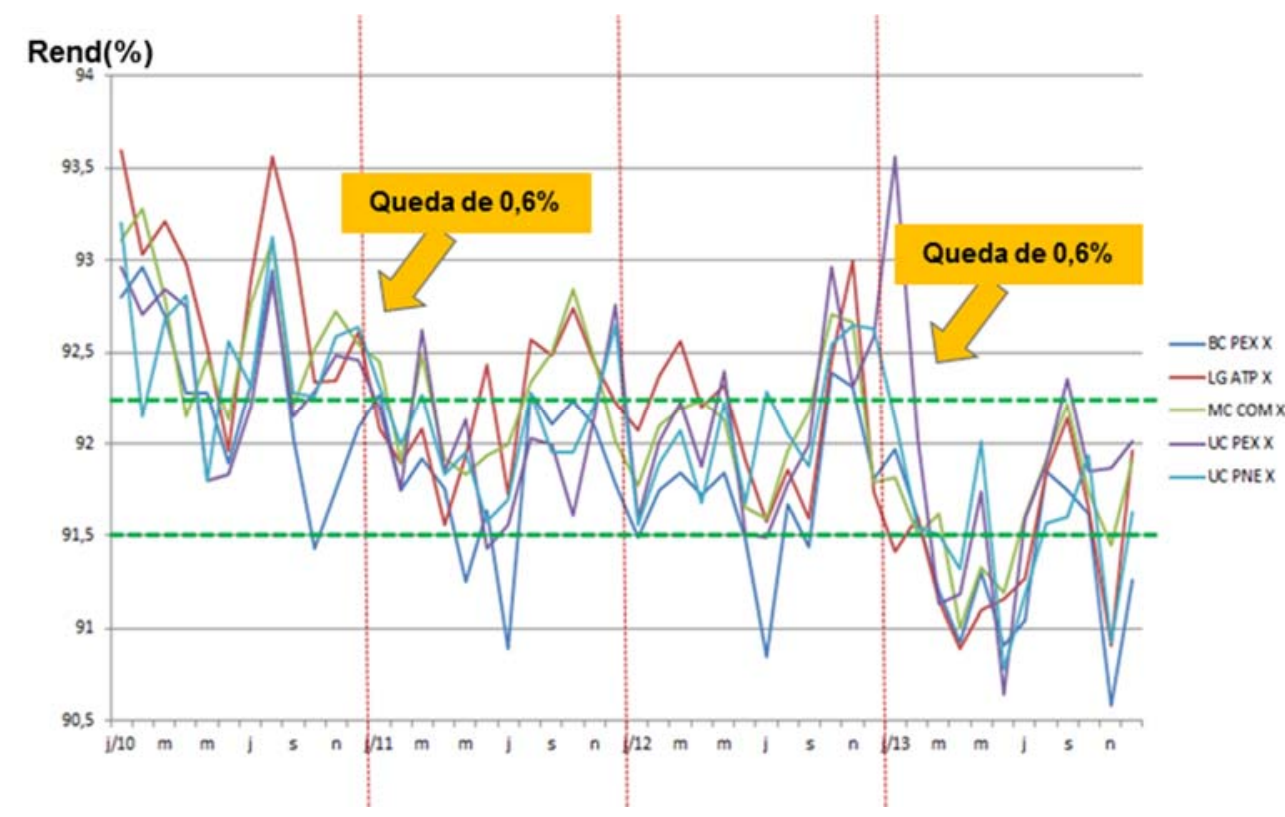

Figura 4. Evolução do rendimento de aço líquido, de 2010 a 2013, para cada tipo de aço

\subsection{RESULTADOS DA $1^{\text {a }}$ ETAPA DE IDENTIFICAÇÃO DE DESVIOS}

Nessa $1^{\text {a }}$ etapa de identificação foram encontrados os seguintes desvios:

$\checkmark$ Sistemática de cálculo do rendimento de aço líquido não estava adequada aos seguintes procedimentos: moldagem do pote de escória; descarte de aço por falta de borda na panela de aço; cessão de aço para outra corrida, através da prática operacional de repanelamento; e retorno de panela com aço do lingotamento contínuo e relingotamento da mesma em outra máquina

$\checkmark$ Falhas na aquisição do peso bruto de panela de aço

$\checkmark$ Falhas na aquisição de pesos de briquete de lama e sucata de forma geral

$\checkmark$ Conceito incorreto no processo de aquisição de tara de panela de aço

\subsection{RESULTADOS DA 2ª ETAPA DE IDENTIFICAÇÃO DE DESVIOS}

Os principais desvios encontrados na $2^{\mathrm{a}}$ etapa de identificação foram:

$\checkmark$ Fator previsto de dedução de escória de gusa muito abaixo do valor real

$\checkmark$ Corridas não críticas sofrendo o processo de "corte no aço" sem necessidade

$\checkmark$ Baixa eficiência do sopro pelo fundo dos convertedores

$\checkmark$ Volume excessivo de escória gerada durante o sopro no convertedor

$\checkmark$ Problemas de precisão de pesagem das panelas com as pontes rolantes

$\checkmark$ Existência de dois procedimentos para pesagem de panela com e sem aço

$\checkmark$ Troca de tampa de panela de aço com a tara já registrada no sistema

$\checkmark$ Tara de panela de aço sem alteração no sistema, após remoção de cascão 


\subsection{IMPLANTAÇÃO DE AÇÕES CORRETIVAS}

Durante o desenvolvimento do projeto, foram implantadas 23 ações corretivas, dentre as quais destacam-se:

$\checkmark$ Gestão equilibrada da cobertura de sola do convertedor LD, otimizando a eficiência do sopro pelo fundo, através das 12 ventaneiras (Figura 5, abaixo)
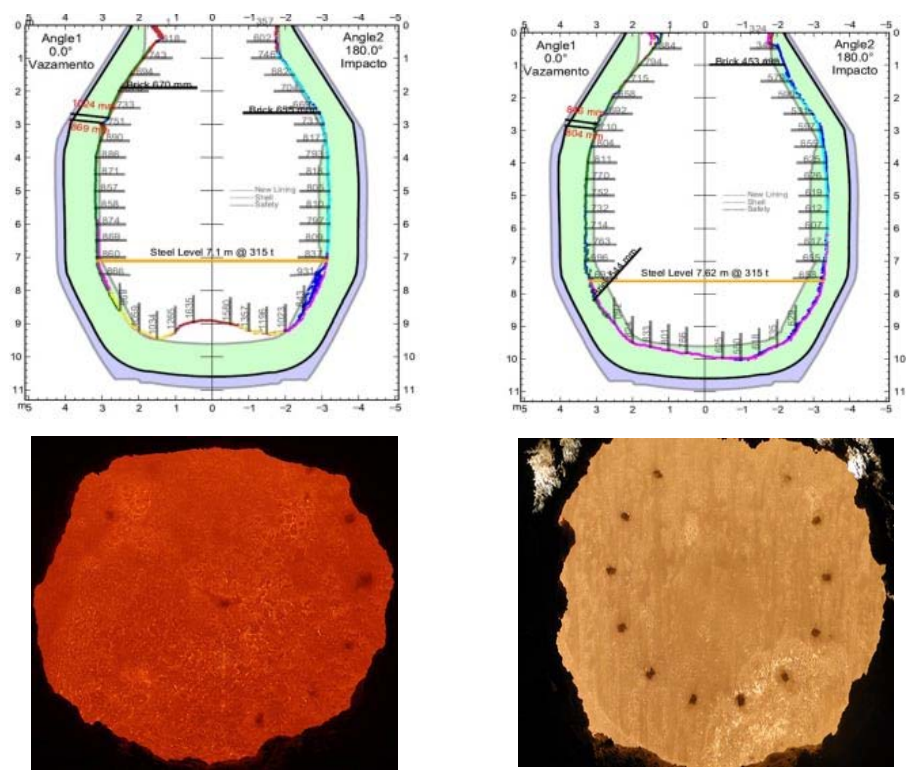

Figura 5. Melhoria na gestão da cobertura de sola do convertedor

$\checkmark$ Implantação de novo modelo de cálculo de fundentes com foco na maximização do peso de aço e minimização de peso de escória (Figura 6)

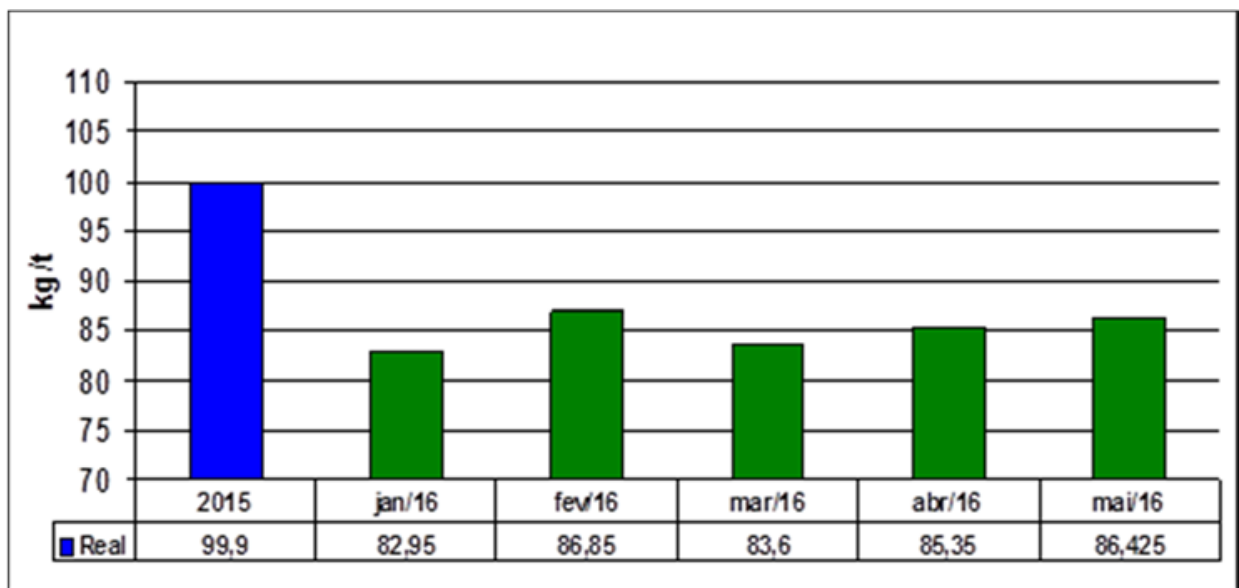

Figura 6. Redução do peso de escória após implantação do novo modelo de fundentes

$\checkmark$ Correção de desvios nos sistemas de pesagem das pontes rolantes, através das seguintes intervenções: alinhamento do conjunto de pesagem; conferência das emendas elétricas; troca do tambor/enrolador de cabos; etc

$\checkmark$ Treinamento para todos os envolvidos com o assunto rendimento 
$\checkmark$ Adequação do fator de dedução de escória presente na panela de gusa

$\checkmark$ Correção dos desvios na aquisição de tara de panela de aço

$\checkmark$ Correção dos desvios na sistemática de cálculo do rendimento

$\checkmark$ Estabelecimento de um padrão fotográfico para remoção de escória da panela de gusa, após o processo de dessulfuração no KR (Figura 7, abaixo)

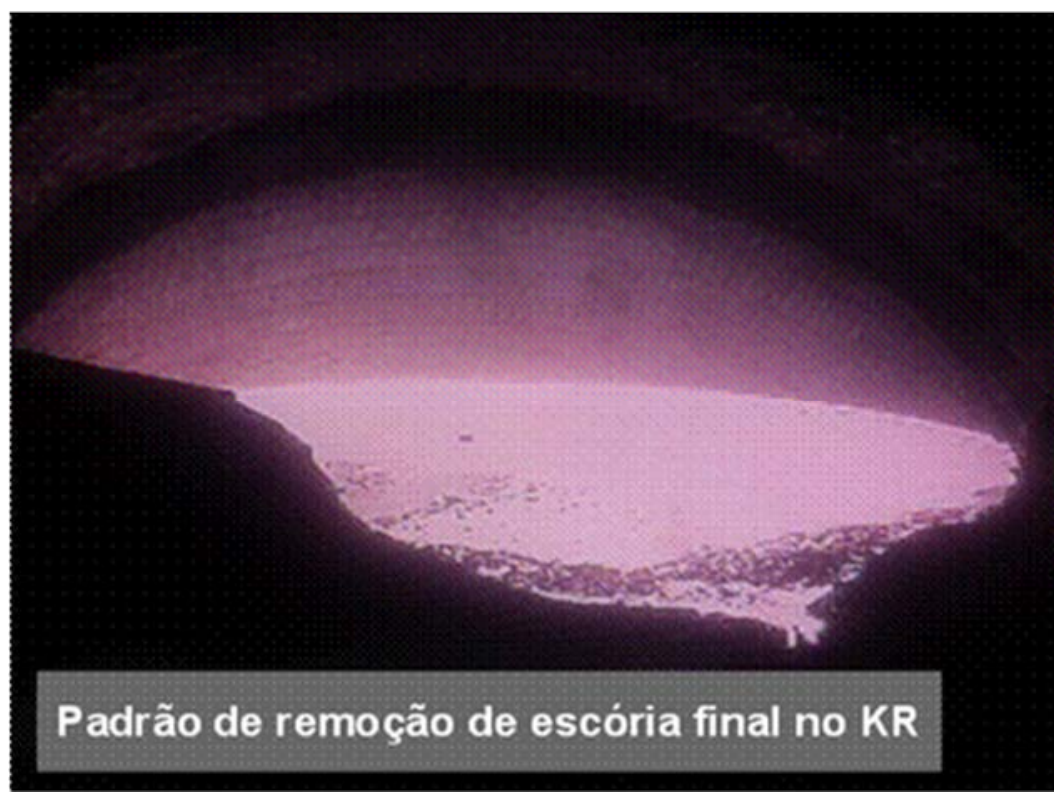

Figura 7. Padrão fotográfico para remoção de escória, após dessulfuração no KR

$\checkmark$ Uniformização dos critérios de estabilização de peso de panela de aço, antes do envio da panela para a torre do lingotamento contínuo (ver Figura 8)

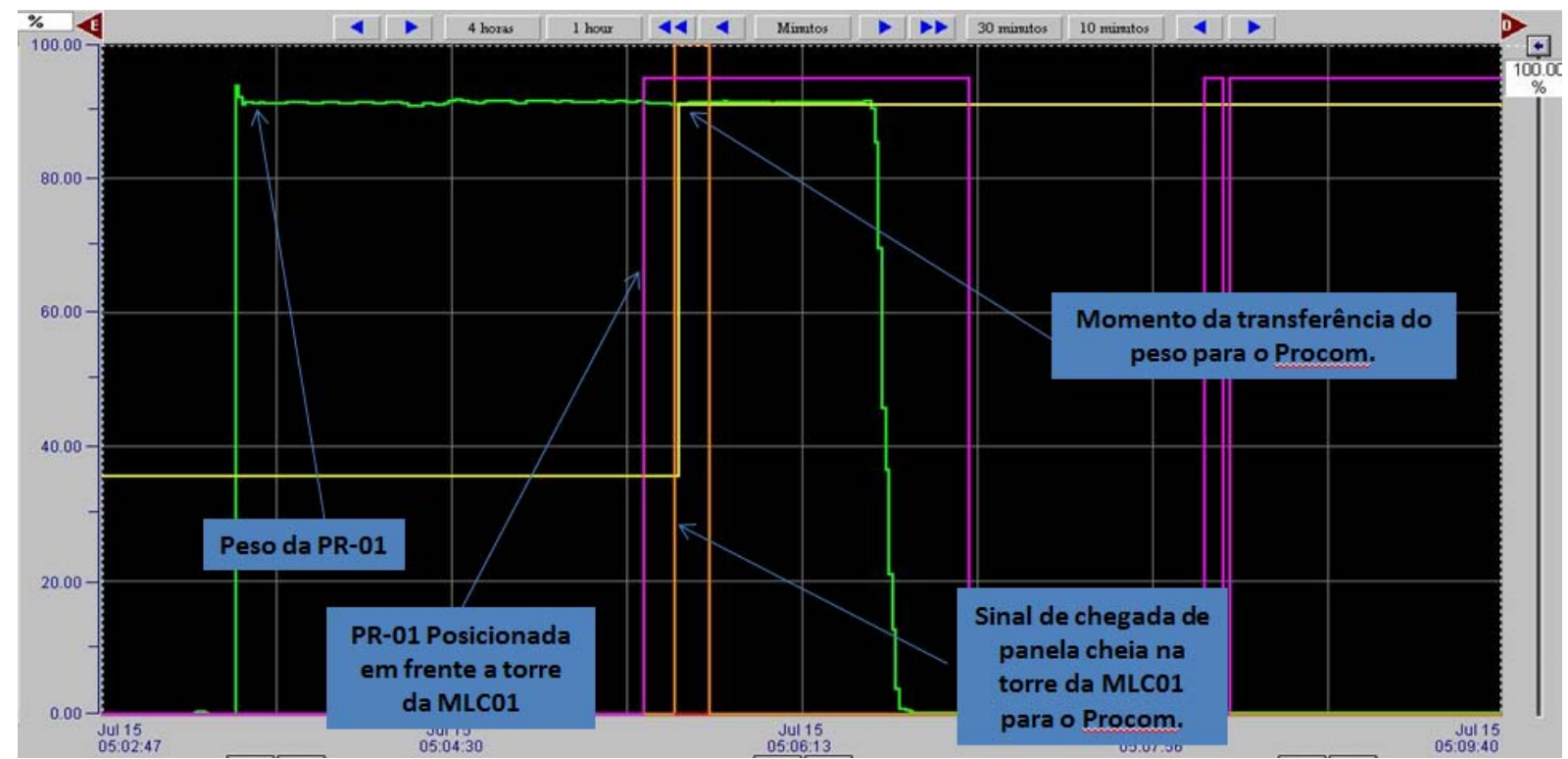

Figura 8. Gráfico mostrando critério de estabilização de peso de panela de aço 


\subsection{RESULTADOS DA OTIMIZAÇÃO DO RENDIMENTO DE AÇO LÍQUIDO}

A Figura 9 mostra a otimização do rendimento de aço líquido, que foi obtida com a implantação do projeto em 2014. O valor do rendimento, que antes do projeto estava em torno de 91,6\%, evoluiu para uma média de 93,5\% em 2015 e 2016. Esse aumento de $1,9 \%$ em média no valor do rendimento de aço líquido proporcionou uma expressiva redução no custo de produção da aciaria.

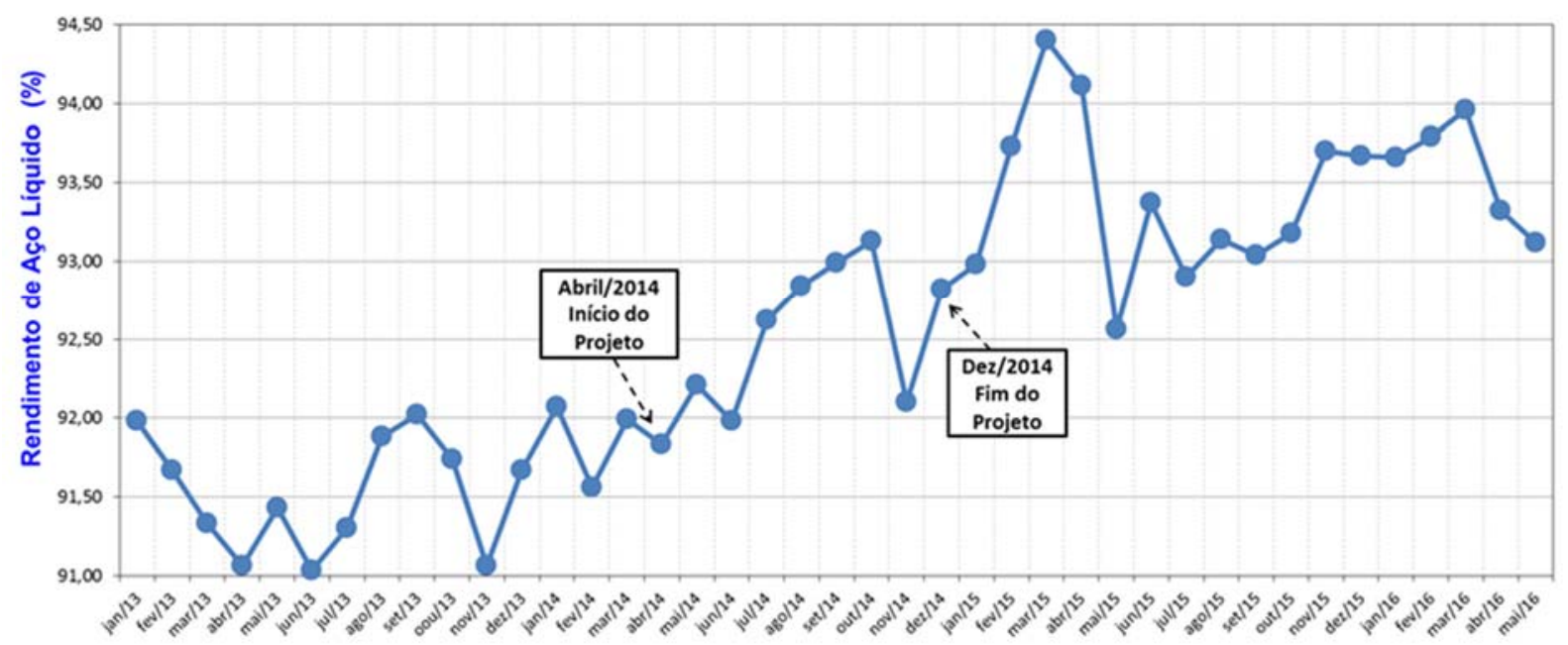

Figura 9. Otimização do rendimento de aço líquido, após implantação do projeto

\section{CONCLUSÃO}

O projeto, apresentado nesse trabalho, foi concluído em 2014, mas continuou apresentando resultados consistentes em 2015 e 2016. Isso demonstra que os diversos desvios existentes no processo foram corretamente identificados e que as ações corretivas implantadas permitiram o "calçamento" do processo de produção que se encontrava associado ao rendimento de aço líquido. Em outras palavras, as ações corretivas garantiram que os resultados alcançados fossem mantidos por um longo período de tempo, o que levou à grande evolução verificada no valor do rendimento de aço líquido.

O experimento realizado, mostrou, de forma clara, que certos desvios só podem ser detectados através de observação "in loco", com o acompanhamento das corridas sendo feito de forma integrada, ou seja, com especialistas em todas as fases do processo de produção, acompanhando as mesmas corridas, ao mesmo tempo.

O aumento de $1,9 \%$ no valor do rendimento de aço líquido proporcionou uma expressiva redução de custo, uma vez que representou uma produção a mais de aço líquido, da ordem de 130.000t/ano. 